14.2

\title{
Механические свойства хитозановых нитей, полученных при различных условиях их формования по коагуляционному методу
}

\author{
(c) Е.Н. Маевская, ${ }^{1}$ Е.Н. Дресвянина, ${ }^{1,2}$ А.Н. Юденко, ${ }^{2}$ В.Е. Юдин ${ }^{1,3}$ \\ ${ }^{1}$ Санкт-Петербургский политехнический университет Петра Великого, \\ 195251 Санкт-Петербург, Россия \\ ${ }^{2}$ Санкт-Петербургский государственный университет промышленных технологий и дизайна, \\ 191186 Санкт-Петербург, Россия \\ ${ }^{3}$ Институт высокомолекулярных соединений РАН, \\ 199004 Санкт-Петербург, Россия \\ e-mail: ma.eka@yandex.ru
}

(Поступило в Редакцию 15 января 2018 г.)

Получены нити из хитозана путем его осаждения (коагуляции) из водного раствора уксусной кислоты в спиртово-щелочную среду. Исследованы влияние молекулярной массы хитозана, скорости подачи раствора полимера, степени фильерной вытяжки на механические свойства получаемых нитей. Установлено, что вязкость растворов хитозана зависит от его молекулярной массы: с увеличением молекулярной массы вязкость раствора увеличивается и соответственно концентрация хитозана в растворе, необходимая для формования волокон, снижается. Определены оптимальные параметры процесса формования. Получены полифиламентные нити с различным диаметром элементарных нитей и их количеством.

DOI: $10.21883 /$ JTF.2018.09.46422.15-18

\section{Введение}

Одним из наиболее перспективных полимеров для использования в биомедицине является хитозан, получаемый из природного полисахарида хитина путем его деацетилирования [1-3]. Хитозан обладает рядом уникальных свойств, таких как биосовместимость, биодеградируемость, бактерицидность, отсутствие цитотоксичности [4]. В настоящее время активно проводятся исследования по получению биоматериалов из хитозана, в том числе раневых тканевых покрытий, волокнистых, пленочных и блочных пористых материалов для клеточных технологий, а также биорезорбируемых хирургических нитей, позволяющих исключить повторные операции по их удалению [5].

Исследования по разработке способа получения волокон и нитей из хитозана было начато в работах $[6,7]$. Показано, что оптимальным растворителем для хитозана является $2 \%$-водный раствор уксусной кислоты; осадителем - спиртово-щелочная смесь, подобраны скорости подачи и скорости сдвига раствора полимера, время осаждения, параметры сушки готового волокна. Кратко описаны структура и свойства получаемых монофиламентных нитей из хитозана.

Целью настоящей работы является исследование влияния молекулярной массы хитозана, скорости подачи раствора хитозана, величины фильерной вытяжки волокон в осадительной ванне на механические свойства получаемых моно- и полифиламентных нитей.

\section{Методы и оборудования}

Для получения нитей использовали хитозан фирмы „Биопрогресс“ (г. Мытищи) с молекулярной мас- сой $65 \cdot 10^{3}$ и степенью деацетилирования 95\%, а также хитозан фирмы „ВiologНерре“ (Германия) с молекулярной массой $210 \cdot 10^{3}$ и степенью деацетилирования $92 \%$. Хитозан растворяли в 2\%-м растворе уксусной кислоты, концентрация хитозана в растворе составляла от 5 до 7\% для хитозана фирмы „Биопрогресс“ и 4\% для хитозана фирмы „BiologHeppe“. Растворы были отфильтрованы и обезвоздушены в течение $24 \mathrm{~h}$.

В работах [6-8] показано, что ориентированная структура волокон из хитозана формируется на стадии прохождения раствора хитозана через фильеру в результате возникающих в ней сдвиговых напряжений. Поэтому для выбора оптимальных параметров формования нитей, обеспечивающих его максимальные прочностные и упругие характеристики, были проведены исследования реологических свойств растворов хитозана. Реологические измерения проводились на реометре Physica MCR 301 фирмы Anton Paar при $20^{\circ} \mathrm{C}$ по методу „цилиндр в цилиндре“ в режиме сдвигового течения при скоростях сдвига $1-4000 \mathrm{~s}^{-1}$.

Нити формовали по коагуляционному методу, осадителем являлась спиртово-щелочная смесь, содержащая $10 \%$-й водный раствор $\mathrm{NaOH}$ и $\mathrm{C}_{2} \mathrm{H}_{5} \mathrm{OH}$ в соотношении $1: 1$ [9]. Формование полифиламентных нитей проводили с использованием фильер с количеством отверстий 12, 24, 30 и диаметром отверстий $200 \mu \mathrm{m}$, а также фильеры с количеством отверстий 100 и диаметром отверстий $100 \mu \mathrm{m}$. Для формования мононитей использовали фильеру диаметром $0.6 \mathrm{~mm}$. Скорость подачи раствора зависела от типа фильеры и варьировала от 3 до $5.0 \mathrm{~mm}^{3} / \mathrm{s}$, время осаждения составляло $150 \mathrm{~s}$; степень фильерной вытяжки $(\lambda)$ изменялась от -20 (усадка) до $+120 \%$ (растяжение), пластификационная вытяжка составляла 20\%. Нить промывали в дистилли- 
рованной воде, во вторую промывочную ванну добавляли катионный ПАВ. Затем нити сушили на воздухе при температуре $50^{\circ} \mathrm{C}$.

Измерения механических свойств (разрывного напряжения, модуля Юнга и деформации при разрушении) проводили с использованием комплекса для исследования механических свойств фирмы „Инстрон“ 5943. Зажимная длина составляла $100 \mathrm{~mm}$. Перед испытаниями нити выдерживались при нормальных климатических условиях (относительной влажности 66\%) не менее $24 \mathrm{~h}$.

\section{Результаты и обсуждения}

Исследования реологических свойств (рис. 1) растворов хитозана показали, что исследуемые растворы

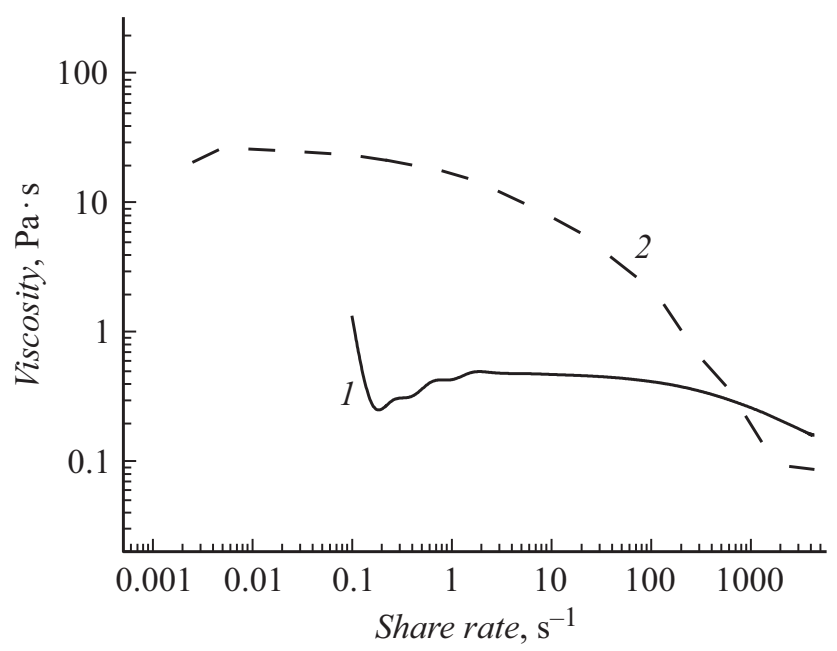

Рис. 1. Зависимости вязкости $4 \%$-х растворов от скорости сдвига для хитозанов с молекулярной массой $65 \cdot 10^{3}$ (1) и $210 \cdot 10^{3}(2)$.

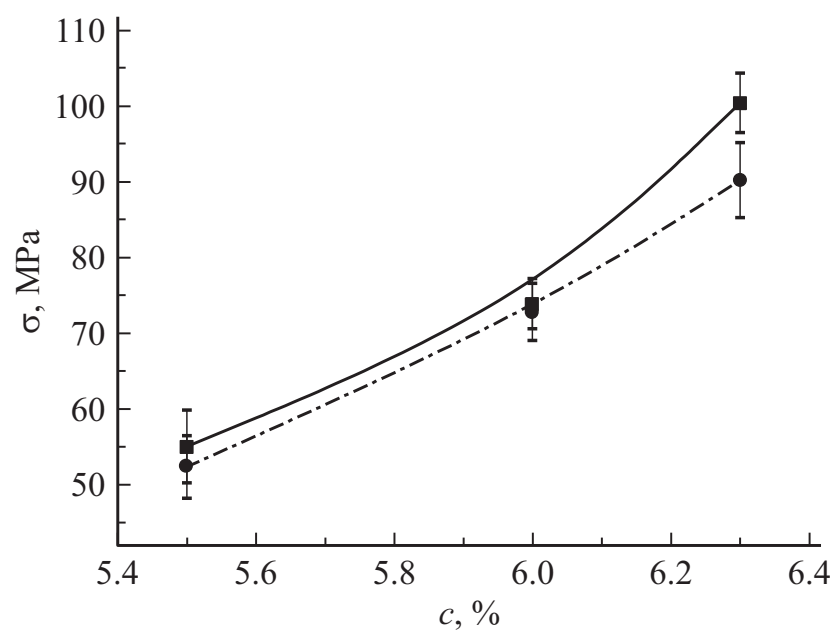

Рис. 2. Зависимость разрывного напряжения $\sigma$ от концентрации $c$ хитозана с молекулярной массой $65 \cdot 10^{3}$ в растворе при значениях фильерной вытяжки $\lambda$, равных 10\% (штрихпунктирная линия) и $30 \%$ (сплошная линия), при скорости подачи раствора $v=5 \mathrm{~mm}^{3} / \mathrm{s}$.
Таблица 1. Скорости сдвига раствора в зависимости от скорости его подачи и количества отверстий в фильере

\begin{tabular}{r|c|c}
\hline Тип фильеры & Скорость подачи, $\mathrm{mm}^{3} / \mathrm{s}$ & Скорость сдвига, $\mathrm{s}^{-1}$ \\
\hline $1 \times 600 \mu \mathrm{m}$ & 5.0 & 118 \\
$1 \times 600 \mu \mathrm{m}$ & 3.3 & 77.8 \\
$12 \times 200 \mu \mathrm{m}$ & 1.7 & 90.23 \\
$24 \times 200 \mu \mathrm{m}$ & 3.3 & 87.58 \\
$30 \times 200 \mu \mathrm{m}$ & 3.3 & 70.06 \\
$100 \times 100 \mu \mathrm{m}$ & 1.7 & 86.62
\end{tabular}

являются неньютоновскими жидкостями; с увеличением скорости сдвига вязкость растворов уменьшается, что свидетельствует об ориентации макромолекул хитозана и формировании анизотропной структуры растворов под действием сдвигового поля [7]. При этом вязкость растворов возрастала при увеличении молекулярной массы хитозана и с увеличением концентрации хитозана в растворе. Так, растворы хитозана с небольшой молекулярной массой („Биопрогресс“) при концентрации хитозана менее $5 \mathrm{wt} . \%$ являются низковязкими жидкостями, при увеличении концентрации хитозана до $7 \mathrm{wt} . \%$ раствор представляет собой гель с высоким условным пределом текучести. Формование волокон и нитей из таких растворов невозможно. Растворы с содержанием хитозана 5.5-6.5 wt.\% обладают необходимыми реологическими и гидродинамическими свойствами, позволяющими подавать их через фильеру, сохраняя ламинарность струи в осадителе. Механические свойства нитей, полученных из растворов хитозана с концентрациями 5.5, 6 и $6.3 \mathrm{wt} . \%$, представлены на рис. 2. Очевидно, что разрывное напряжение нитей возрастает при увеличении концентрации хитозана в растворе, нити с наилучшими механическими свойствами были получены из растворов с концентрацией хитозана $6.3 \mathrm{wt} . \%$.

Аналогичные исследования были проведены для хитозана с большей молекулярной массой (фирмы

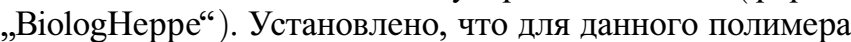
оптимальной является концентрация 4 wt.\%.

В результате проведенных исследований было также показано, что скорость сдвига, возникающая при прохождении раствора через фильеру, и соответственно скорость подачи раствора влияют на механические свойства получаемых нитей. Авторами [7] ранее был определен диапазон скоростей сдвига $\dot{\gamma}$, возникающих в фильере: от 20 до $190 \mathrm{~s}^{-1}$. Используя формулу [7] $\dot{\gamma}=\frac{2 Q}{\pi R^{3}}$, где $Q-$ скорость подачи раствора, $R-$ радиус фильеры, можно рассчитать необходимую скорость подачи раствора (табл. 1). При использовании фильеры радиусом $R=0.3 \mathrm{~mm}$ необходимая скорость подачи раствора будет находиться в интервале от 0.8 до $8 \mathrm{~mm}^{3} / \mathrm{s}$. На рис. 2 представлены значения механических свойств нитей из хитозана фирмы „Биопрогресс“, полученных при скоростях подачи раствора 3.3 и $5.0 \mathrm{~mm}^{3} / \mathrm{s}$, что соответствует скоростям сдвига 77.8 и $118 \mathrm{~s}^{-1}$. Наилучшими прочностными характеристиками обладают нити, сформованные при скорости подачи $3.3 \mathrm{~mm}^{3} / \mathrm{s}$ (рис. 3 ). 

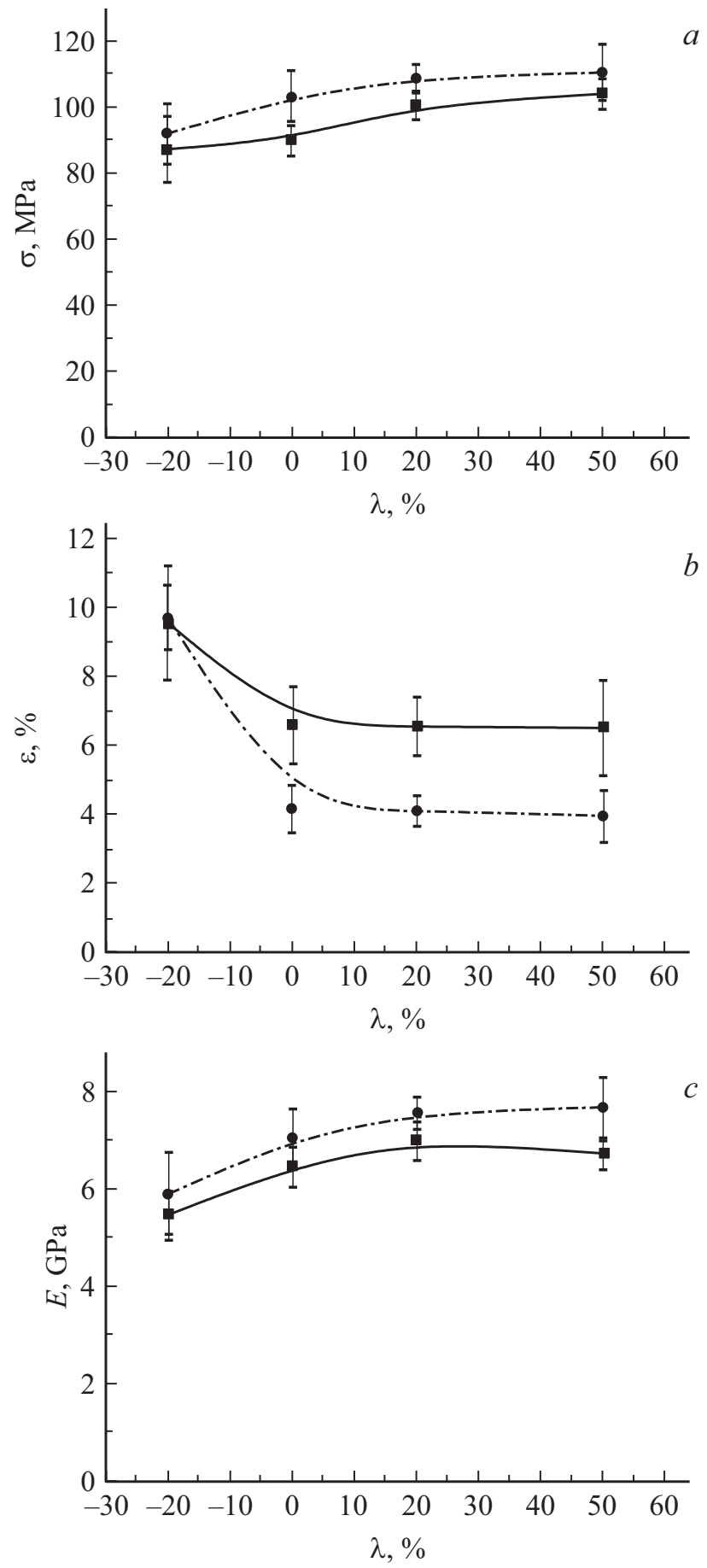

Рис. 3. Зависимости разрывного напряжения $\sigma(a)$, относительной деформации $\varepsilon(b)$ и модуля Юнга $E(c)$ хитозана с молекулярной массой $65 \cdot 10^{3}$ от величины фильерной вытяжки $\lambda$ для скоростей подачи раствора $v=3.3$ (штрихпунктирная линия) и $5.0 \mathrm{~mm}^{3} / \mathrm{s}$ (сплошная линия).

Значительное влияние на механические свойства нитей оказывает величина фильерной (ориентационной) вытяжки $\lambda$. Структурирование раствора хитозана и ориентация макромолекул хитозана происходят при прохождении раствора через фильеру и, как следствие, образуется упорядоченная анизотропная структура волокна, что характерно для полужестко- и жесткоцепных полимеров [6]. Для хитозана с небольшой молекулярной массой („Биопрогресс“) вытяжка 20-30\% уже является достаточной для образования ориентированной структуры нити, дальнейшее увеличение вытяжки не сопро-
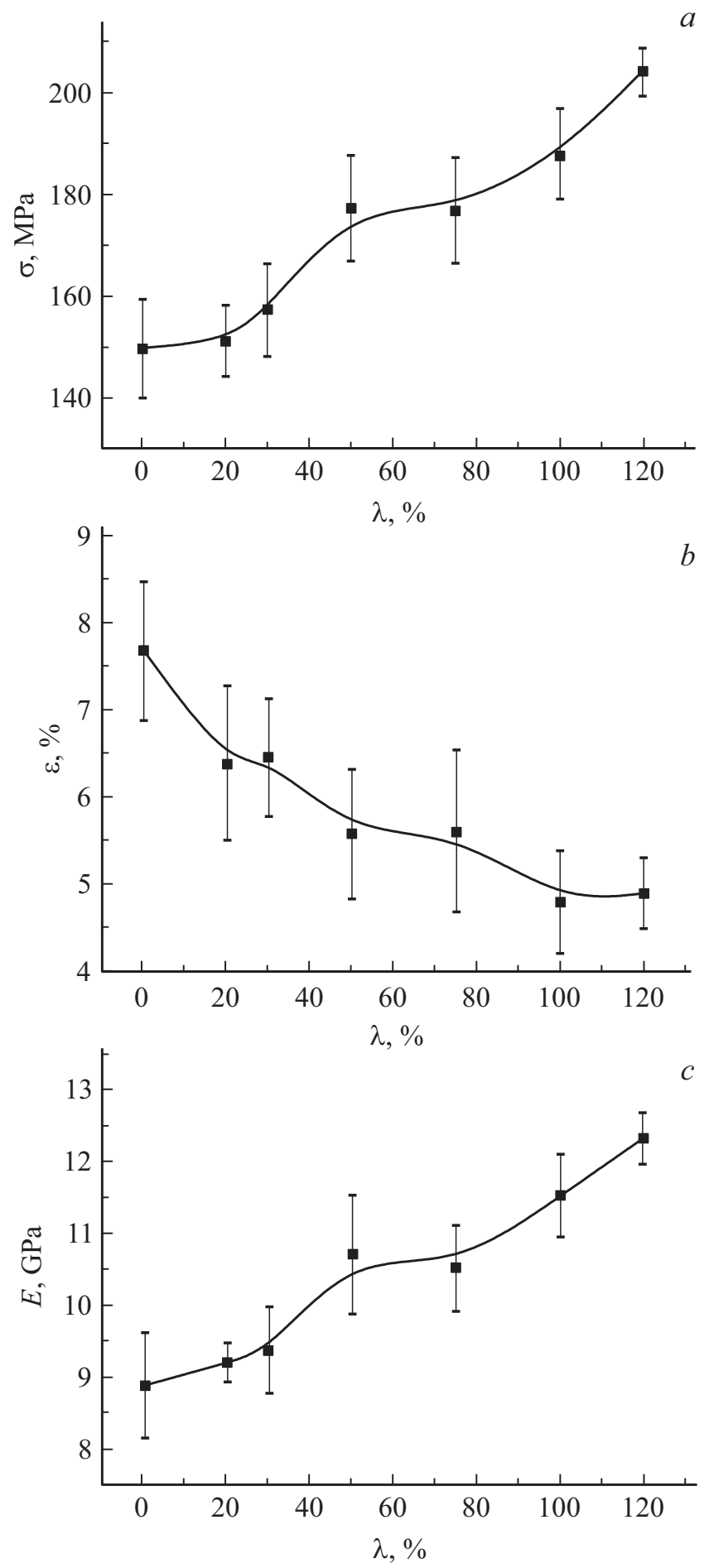

Рис. 4. Зависимости разрывного напряжения $\sigma(a)$, относительной деформации $\varepsilon(b)$ и модуля Юнга $E(c)$ от величины фильерной вытяжки $\lambda$ для хитозана с молекулярной массой $210 \cdot 10^{3}$. Скорость подачи раствора $v=3.3 \mathrm{~mm}^{3} / \mathrm{s}$. 
вождается улучшением механических свойств (рис. 3), а лишь приводит к обрыву нити при формовании. Иная ситуация наблюдается для хитозана с большей молекулярной массой (фирмы „ВiologНерре“). Механические свойства нитей из данного полимера в значительной степени зависят от величины фильерной вытяжки (рис. 4): ее увеличение приводит к росту разрывного напряжения $\sigma$ и модуля Юнга $E$ и снижению удлинения при разрыве $\varepsilon$. Максимальным значением вытяжки является $\lambda=120 \%$. При этом разрывное напряжение и модуль Юнга для нитей, сформованных из растворов хитозана с большей молекулярной массой, значительно выше, чем для нитей, полученных из хитозана с меньшей молекулярной массой.

Таким образом, в результате проведенных исследований были определены оптимальные условия формования хитозановых нитей коагуляционным методом: скорость подачи раствора $3.3 \mathrm{~mm}^{3} / \mathrm{s}$, что соответствует скорости сдвига раствора в фильере $77.8 \mathrm{~s}^{-1}$, фильерная вытяжка $20-40 \%$ для хитозана с молекулярной массой $65-10^{3}$ и $100-120 \%$ для хитозана с молекулярной массой $210 \cdot 10^{3}$.

Учитывая подобранные условия формования, были получены полифиламентные нити (табл. 2). При формовании полифиламентных нитей скорость подачи устанавливалась таким образом, чтобы скорость сдвига раствора в фильере находилась в интервале $70-90 \mathrm{~s}^{-1}$ (табл. 1). Фильерная вытяжка составляла $20 \%$ для хитозана с меньшей молекулярной массой („Биопрогресс“) и $50 \%$ для хитозана с большей молекулярной массой („BiologHeppe“).
Показано, что разрывное напряжение и модуль Юнга для полифиламентной нити ниже, чем для мононити, полученной при аналогичных условиях, вследствие неодновременности разрыва элементарных нитей в пучке. Количество элементарных нитей не оказывает существенного влияния на разрывное напряжение и модуль Юнга, при этом значение абсолютной разрывной нагрузки возрастала при увеличении количества элементарных нитей.

\section{Выводы}

Получены моно- и полифиламентные нити из водных растворов хитозана в $2 \%-и ̆$ уксусной кислоте, осадитель - спиртово-щелочная смесь. Механические свойства полученных нитей зависят от молекулярной массы хитозана - с увеличением молекулярной массы прочность нити увеличивается. Механические свойства волокон зависят также от условий их формования. Так, максимальной прочностью обладают волокна, полученные при скорости подачи раствора $3.3 \mathrm{~mm}^{3} / \mathrm{s}$. Кроме того, прочность волокон растет с увеличением степени их вытяжки в осадительной ванне: максимальная вытяжка составляет $20-40 \%$ для хитозана с меньшей молекулярной массой и $120 \%$ для хитозана с большей молекулярной массой. Получены полифиламентные нити с различным количеством элементарных нитей и показано, что разрывное напряжение и модуль Юнга полифиламентной нити практически не зависят от количества элементарных нитей.

Таблица 2. Зависимость прочностных характеристик от молекулярной массы полимера и количества отверстий в фильере

\begin{tabular}{|c|c|c|c|}
\hline $\begin{array}{c}\text { Количество } \\
\text { отверстий }\end{array}$ & Характеристики нити & „Биопрогресс“ & „BiologHeppe“ \\
\hline 12 & $\begin{array}{l}\text { Линейная плотность, tex } \\
\text { Напряжение при разрыве } \sigma, \mathrm{MPa} \\
\text { Модуль Юнга } E, \mathrm{GPa} \\
\text { Относительная деформация } \varepsilon, \% \\
\text { Максимальная нагрузка, N }\end{array}$ & $\begin{array}{r}35.3 \\
74.8 \\
4.9 \\
5.3 \\
2.0\end{array}$ & $\begin{array}{r}24.96 \\
125.97 \\
9.16 \\
3.12 \\
2.68\end{array}$ \\
\hline 24 & $\begin{array}{l}\text { Линейная плотность, tex } \\
\text { Напряжение при разрыве } \sigma, \mathrm{MPa} \\
\text { Модуль Юнга } E, \mathrm{GPa} \\
\text { Относительная деформация } \varepsilon, \% \\
\text { Максимальная нагрузка, N }\end{array}$ & $\begin{array}{l}51.6 \\
88.5 \\
6.45 \\
3.6 \\
3.5\end{array}$ & $\begin{array}{r}44.95 \\
155.57 \\
10.81 \\
4.66 \\
5.14\end{array}$ \\
\hline 30 & $\begin{array}{l}\text { Линейная плотность, tex } \\
\text { Напряжение при разрыве } \sigma, \mathrm{MPa} \\
\text { Модуль Юнга } E, \mathrm{GPa} \\
\text { Относительная деформация } \varepsilon, \% \\
\text { Максимальная нагрузка, } \mathrm{N}\end{array}$ & $\begin{array}{r}89.9 \\
90.0 \\
5.9 \\
5.2 \\
5.8\end{array}$ & $\begin{array}{r}67.43 \\
133.23 \\
9.63 \\
4.32 \\
6.61\end{array}$ \\
\hline 100 & $\begin{array}{l}\text { Линейная плотность, tex } \\
\text { Напряжение при разрыве } \sigma, \mathrm{MPa} \\
\text { Модуль Юнга } E, \mathrm{GPa} \\
\text { Относительная деформация } \varepsilon, \% \\
\text { Максимальная нагрузка, } \mathrm{N}\end{array}$ & $\begin{array}{l}55.8 \\
86.54 \\
4.76 \\
7.6 \\
7.6\end{array}$ & $\begin{array}{c}27.3 \\
121.63 \\
6.3 \\
6.57 \\
2.44\end{array}$ \\
\hline
\end{tabular}


Разрабатываемые моно- и полифиламентные нити могут быть использованы в качестве резорбируемых шовных нитей, а также в качестве матриц для клеточных и тканезамещающих технологий, восстановления поврежденной нервной ткани.

Исследование поддержано грантом РНФ № 14-3300003.

\section{Список литературы}

[1] Немщев С.В. Комплексная технология хитина и хитозана из панциря ракообразных. М.: ВНИРО, 2006. 134 с.

[2] Islam S., Rahman Bhuiyan M.A., Islam M.N. // J. Polym. Environ. 2017. Vol. 25. N 3. P. 854-866. DOI: $10.1007 / \mathrm{s} 10924-$ 016-0865-5

[3] Abdou E.S., Nagy K.S., Elsabee M.Z. // Bioresource Technol. 2008. Vol. 99. N 5. P. 1359-1367.

DOI: 10.1016/j.biortech.2007.01.051

[4] Furuike T., Nagahama H., Chaochai T., Tamura H. // Fibers. 2015. Vol. 3. P. 380-393. DOI: 10.3390/fib3040380

[5] Агаджсанян В.В., Пронских А.А., Демина В.А., Гомзяк В.И., Седуш Н.Г., Чвалун С.Н. // Политравма. 2016. C. 85-93. [Agadzhanyan V.V., Pronskikh A.A., Demina V.A., Gomzyak V.I., Sedush N.G., Chvalun S.N. // Polytrauma. 2016. P. 85-93.]

[6] Дресвянина Е.Н., Добровольская И.П., Внучкин А.В., Попрядухин П.В. // Изв. вузов. Технология легкой промышленности. 2011. Т. 11. № 1. С. 48-51.

[7] Dresvyanina E.N., Dobrovol'skaya I.P., Popryadukhin P.V., Yudin V.E., Ivan'kova E.M., Elokhovskii V.Y., Khomenko A.Y. // Fibre Chem. 2013. Vol. 44. N 5. P. 280-283.

[8] Агеев Е.П., Вихорева Г.А., Зоткин М.А., Матушкина Н.Н., Герасимов В.И., Зезин С.Б., Оболонкова Е.С. // Высокомолек. соед. 2004. Т. 46. С. 2035-2041.

[9] Маевская Е.Н., Юденко А.Н., Дресвянина Е.Н., Юдин B.E. // Тез. докл. II росс. конф. с международным участием „Физика - наукам о жизни“. Санкт-Петербург, 2017. C. 108 